\title{
Plasticity at the DNA recognition site of the MeCP2 mCG-binding domain
}

\author{
Ming Lei ${ }^{1,2}$, Wolfram Tempel ${ }^{2}$, Ke $\operatorname{Liu}^{1,2^{*}}$ and Jinrong $\operatorname{Min}^{1,2,3 *}$
}

1. Hubei Key Laboratory of Genetic Regulation and Integrative Biology, School of Life

Sciences, Central China Normal University, Wuhan 430079, PR China

2. Structural Genomics Consortium, University of Toronto, Toronto, Ontario M5G 1L7, Canada

3. Department of Physiology, University of Toronto, Toronto, Ontario M5S 1A8, Canada

* Correspondence should be addressed to K. L (Email: keliu2015@mail.ccnu.edu.cn)or J.M. (Email: jr.min@utoronto.ca) 


\begin{abstract}
$\mathrm{MeCP} 2$ is an abundant protein, involved in transcriptional repression by binding to $\mathrm{CG}$ and non-CG methylated DNA. However, MeCP2 might also function as a transcription activator as $\mathrm{MeCP} 2$ is found bound to sparsely methylated promoters of actively expressed genes. Furthermore, Attachment Region Binding Protein (ARBP), the chicken ortholog of $\mathrm{MeCP} 2$, has been reported to bind to Matrix/scaffold attachment regions (MARs/SARs) DNA with an unmethylated 5'-CAC/GTG-3' consensus sequence. In this study, we investigated how $\mathrm{MeCP} 2$ recognizes unmethylated 5'-CAC/GTG-3' motif containing DNA by binding and structural studies. We found that MeCP2-MBD binds to MARs DNA with a comparable binding affinity to mCG DNA, and the MeCP2CAC/GTG complex structure revealed that MeCP2 residues R111 and R133 form basespecific interactions with the GTG motif. For comparison, we also determined crystal structures of the MeCP2-MBD bound to $\mathrm{mCG}$ and mCAC/GTG DNA, respectively. Together, these crystal structures illustrate the adaptability of the MeCP2-MBD toward the GTG motif as well as the mCG DNA, and also provide structural basis of a biological role of $\mathrm{MeCP} 2$ as a transcription activator and its disease implications in Rett syndrome.
\end{abstract}




\section{Introduction}

The discovery of MeCP2 as a nuclear, methyl-CpG DNA binding protein in 1992 is a major breakthrough in the field of DNA methylation ${ }^{1}$. In addition to its methyl-cytosinebinding domain $(\mathrm{MBD})^{2}$, the MeCP2 protein also contains a NCoR/SMRT interaction domain (NID), which recruits the NCoR/SMRT corepressor complex to chromatin ${ }^{3,4}$, hence linking DNA methylation to histone deacetylation and transcriptional repression.

The MECP2 gene is located on the $\mathrm{X}$ chromosome in band 28 (Xq28), and ubiquitously expressed. In neurons, $\mathrm{MeCP} 2$ protein levels are comparable to histones ${ }^{5}$, suggesting a critical role in neuron development, and consistent with a link between MECP2 mutations and Rett syndrome (RTT), a progressive X-linked neurological disorder almost exclusively found in girls ${ }^{6}$. Mutations or duplications of $M E C P 2$ have also been found in patients with other neurological and autoimmune disorders ${ }^{7}$.

MeCP2 binding to chromatin was initially thought to depend on mCG density ${ }^{5}$. Subsequently, MeCP2 was also detected bound to non-CG methylated DNA ${ }^{8-11}$, and MeCP2 binding to both CG and non-CG methylated DNA contributes to transcriptional repression $^{8-10,12}$. However, two other studies in either human neuronal SH-SY5Y cells ${ }^{13}$ or mouse hypothalamus ${ }^{14}$ reveal that the majority of genes are actively expressed with $\mathrm{MeCP} 2$ bound to their sparsely methylated promoters. Hence, MeCP2 may serve as a transcription repressor or activator in DNA methylation dependent or independent manners, respectively. This raises the question of how MeCP2 is able to bind to both methylated and unmethylated DNA. Interestingly, even before MeCP2 was identified as a methyl-CG binding protein, Attachment Region Binding Protein (ARBP), the chicken ortholog of human MeCP2 whose MBD domains share $100 \%$ sequence identity ${ }^{15}$, was found attached to Matrix/scaffold attachment regions (MARs/SARs) that lacked any methylated CG dinucleotides ${ }^{15-17}$. DNase I footprint analysis coupled with mutagenesis analysis showed that chicken $\mathrm{MeCP} 2$ specifically recognizes a sequence motif of 5'GGTGT-3' on MARs/SARs ${ }^{15,17}$. The central GTG trinucleotide is critical for the high affinity binding of the MARs DNA to chicken MeCP2, and mutating either of its guanine bases significantly reduced its binding to $\mathrm{MeCP} 2^{15,17}$. Genes flanked by MARs exhibit elevated expression to some different extents ${ }^{18-22}$. 
The complex structure of the MeCP2 MBD with symmetrically methylated CG DNA has been reported before ${ }^{23}$, however it is still unclear how MeCP2 recognizes unmethylated MARs DNA. In this study, we demonstrated the binding characteristics of MeCP2 to MARs DNA using ITC binding assays and structural analysis coupled with mutagenesis studies. Our findings presented here explain why MeCP2 selectively binds GTGcontaining DNA as well as mCG DNA, and also provide a mechanistic insight into the biological role of MeCP2 as a transcription activator and its disease implications in Rett syndrome.

\section{Results}

\section{MeCP2 binds unmethylated MARs DNA with high affinity}

The selectivity of the MeCP2-MBD toward methylated CG DNA has been quantified using different synthetic DNA sequences and structural analysis of the MeCP2-MBD in complex with a mCG-containing DNA fragment from the promoter of the mouse brainderived neurotrophic factor $(B D N F)^{23,24}$. Nevertheless, the physiological context of the MeCP2-MBD binding to unmethylated DNA has not been settled. By means of electrophoretic mobility shift assay (EMSA), the Strätling group showed that ARBP (or chicken MeCP2) binds to a fragment of chicken lysozyme MARs by recognizing the DNA's central 5'-GTG-3' motif ${ }^{15-17}$. A similar ARBP-binding site has also been shown on mouse satellite $\mathrm{DNA}^{15}$. Other groups, however, propose that the binding of MeCP2 to unmethylated DNA might be incidental to the MBD's core function of binding to methylated $\mathrm{DNA}^{25}$, i.e., the incidental binding of MeCP2 to unmethylated DNA would facilitate eventual binding to methylated DNA in vivo ${ }^{1}$.

In order to reconcile the contradictory interpretations of $\mathrm{MeCP} 2$ binding to unmethylated DNA, we first measured the affinity of the MeCP2-MBD to a 16 mer (5' GTGCAGGTGTCCTTAA-3') DNA fragment from a chicken lysozyme MARs by ITC at approximately $2.8 \mu \mathrm{M}$ (Fig. 1a), which is comparable to its affinity to an mCG DNA

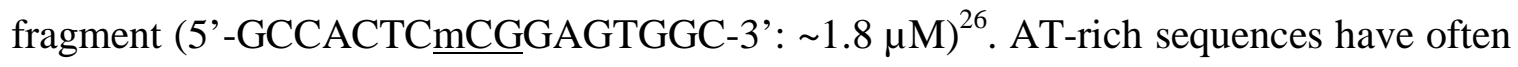


been found near the 5'-GTG-3' consensus sequence and are thought to enhance their binding to $\mathrm{MeCP} 2^{15,16}$. Interestingly, replacing the surrounding AT sequence of the CAC/GTG trinucleotide in the MARs with a sequence similar to that of the 16 mer mCG DNA (5'-GCCCTGGTGTAGTGGC-3': 3.8 $\mu \mathrm{M}$, Fig. 1a, b), barely changed its affinity, confirming that MeCP2 binds to the MARs DNA mainly through the central CAC/GTG $\operatorname{motif}^{17}$.

\section{Structural basis of MeCP2 binding to unmethylated CAC/GTG DNA}

In order to understand the structural basis of the specific recognition of unmethylated DNA by the MeCP2-MBD, we attempted crystallization of the MeCP2-MBD in complex with different unmethylated DNA fragments that were centered a CAC/GTG trinucleotide motif, and obtained high resolution complex crystals with a $12 \mathrm{mer}$ CAC/GTG DNA. As a comparison, we also determined the complex structure of the MeCP2 MBD with a 12mer palindromic mCG DNA. Detailed data collection and structure refinement statistics are listed in Table 1.

In the MeCP2-CAC complex structure (Fig. 2a-c), the MeCP2-MBD displays the canonical fold of a three-stranded $\beta$-sheet with a $\mathrm{C}$-terminal $\alpha$-helix packed against it. The $\beta$-sheet inserts into the major groove of the CAC DNA, consistent with the MeCP2mCG structure presented here and other published MeCP2-mCG structures (Fig. 2d-f) ${ }^{23,27}$. In the MeCP2-CAC crystal structure, bases of only the CAC/GTG motif directly interact with $\mathrm{MeCP} 2$, confirming the importance of the central CAC/GTG trinucleotide in binding to MeCP2 (Fig. 2a-c). Arginine finger residues 111 and 133, which interact with the critical CAC/GTG motif all reside in the $\beta$-sheet core (Fig. 2a-c). Specifically, R111, rigidified by a salt bridge with D121, recognizes the TG dinucleotide of the GTG motif in a stair motif binding mode (Fig. 2a-c). R133 forms hydrogen bonds with the bases of the GTG motif's 5'-teminal GT dinucleotide (Fig. 2a-c). In the MeCP2-mCG structure, on the other hand, arginine fingers R111 and R133 each recognize one mCG dinucleotide from the complementary DNA strands to form a pseudo-symmetric protein-DNA interface (Fig. 2d-f) ${ }^{23}$. 


\section{Structural basis of a mild preference of MeCP2 toward methylated mCAC over CAC DNA}

CG sites are the major cytosine methylation sites, but non- $\mathrm{CG}(\mathrm{CH}, \mathrm{H}=\mathrm{A}, \mathrm{T}$, or $\mathrm{C})$ sites are also subject to cytosine methylation, especially in embryonic stem cells and neurons ${ }^{8,28}$. Among the non-CG sites, the trinucleotide CAC motif is the most prominent modification site, forming $\mathrm{mCAC}^{8}$. It was reported recently that $\mathrm{MeCP} 2$ binding to chromatin is dependent on the total methylation density of both $\mathrm{mCG}$ and $\mathrm{mCAC}$ in mouse brain ${ }^{10}$. Our ITC results indicate that the MeCP2-MBD binds to a mCAC DNA with an affinity of $\sim 0.9 \mu \mathrm{M}$, slightly tighter than to the MARs DNA (Fig. 1a , b) ${ }^{26}$. In order to address the recognition difference of $\mathrm{mCAC}$ and $\mathrm{CAC}$ by $\mathrm{MeCP} 2$, we determined a complex structure of the MeCP2-MBD with a 12mer mCAC/GTG DNA (Table 1).

The MeCP2-mCAC/GTG structure is very similar to that of MeCP2-CAC/GTG, with an RMSD of $0.4 \AA$ over all the aligned $\mathrm{C} \alpha$ atoms (Fig. 2g-i and 3a) and largely conserved GTG recognition (Fig. 2h, i). However, the mCAC 5-methyl group points toward the main chain carbonyl oxygen of R133 with a C-O distance of approximately $3.4 \AA$ (Fig. $2 \mathrm{~g}, \mathrm{~h}$ and $3 \mathrm{a}$ ). This arrangement may represent a weak hydrogen bond, similar to those involving side chain methyl groups in proteins ${ }^{29}$, and might explain why MeCP2 binds to mCAC slightly more tightly than to CAC DNA (Fig. 1a, b) ${ }^{26}$. In both MeCP2mCAC/CAC structures, the GTG trinucleotide appears to be the dominant driver of protein-DNA binding (Fig. 2b, h), which is consistent with the observation that 5hydroxymethylation of a central hmCA motif has little or no effect on recognition by $\mathrm{MeCP} 2^{11}$.

Recently we also solved the MBD2-mCAC/GTG and MBD2-CAC/GTG structures ${ }^{26}$. The major difference between the MeCP2 and MBD2 structures is that the second arginine finger R188 in MBD2 (corresponding to R133 in MeCP2) does not interact with the thymine base of the GTG motif. Instead, it forms hydrogen bonds with the first guanine of the GTG motif and the preceding adenine (Fig. 3c) ${ }^{26}$. In the MeCP2- mCAC/CAC structures, the second arginine finger R133 closely interacts with the GT dinucleotide of 
the GTG motif (Fig. 3c), which is consistent with slightly stronger binding of GTGcontaining DNA to MeCP2 than to MBD2 $2^{26}$. These two recognition modes of the second arginine finger are diverse from that observed in palindromic $\mathrm{mCG}$ complexes, in which the second arginine finger contributes to a pseudo-symmetric protein-DNA interface, as

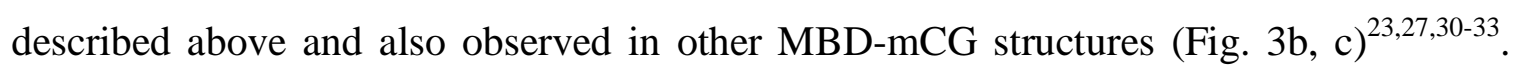
These observations confirm our previous assertion that the second arginine finger, such as $\mathrm{R} 133$ in MeCP2, is more flexible than the first arginine finger, like R111 in MeCP2, to enable a broader binding DNA selectivity spectrum ${ }^{26}$.

\section{Effects of Rett Syndrome mutations of MeCP2 on its binding to mCG and GTG DNA}

Based on our structural studies, R111 and R133 of MeCP2 are the two most critical residues in DNA binding. Mutations of R111 and R133 have been found in Rett Syndrome patients, and R133 is a Rett Syndrome hotspot mutation point ${ }^{34}$. It has been reported that both $\mathrm{R} 111 \mathrm{G}$ and $\mathrm{R} 133 \mathrm{C}$ mutations of $\mathrm{MeCP} 2$ weaken its binding to $\mathrm{mCG}$ DNA as measured by gel mobility shift assays ${ }^{35}$. We investigated here how the R111 and R133 mutations of MeCP2 affect its binding to both mCG and GTG DNA by measuring the binding affinities of the R111G, R111A, R133C and R133A mutants to various DNAs. As expected, the R111G and R111A mutations of MeCP2 disrupted its binding to either GTG or methylated DNA (Fig. 4a, b), consistent with our previous report that the first arginine finger is the major contributor to DNA binding by $\mathrm{MBDs}^{26}$. Neither the R133C nor R133A mutants of MeCP2 measurably bound to CAC/GTG DNA, but they still retained significant binding to methylated DNAs, including mCAC/GTG and mCG DNA (Fig. 4c, d). As mentioned above, the side chain of R133 forms hydrogen bonds with the GT dinucleotide in the GTG motif (Fig. 2b, h). However, in the MeCP2mCAC/GTG structure, the main chain of R133 may also form an additional, weak hydrogen bond with the methyl group from the methylated cytosine (Fig. $2 \mathrm{~h}$ and $3 \mathrm{a}$ ), which would be absent in the MeCP2-CAC/GTG structure (Fig. 2b and 3a). Although mutating R133 into cystine or alanine disrupts its side chain interactions, interactions of the main chain, such as one of the carbonyl oxygen, would not be directly affected. Thus, it seems that the concurrent loss of both side and main chain interactions may render 
R133 mutants incapable of binding unmethylated CAC/GTG DNA. One potential mechanism of the $\mathrm{MeCP} 2$ mutations leading to the Rett Syndrome may be due to their loss of DNA binding ability. The observations that the R133 mutants are still able to bind to $\mathrm{mCG}$ and mCAC/GTG, but not to CAC/GTG, led us to speculate that the unmethylated CAC/GTG DNAs are a physiological ligand of MeCP2 in neurons, and the disrupted binding between them might play a role in the Rett Syndrome. This implication needs further investigation in the future.

In addition to R111 and R133, many other RTT-associated mutations have been mapped to the MeCP2-MBD (Fig. 5a) ${ }^{35-38}$, and most of them have been reported to reduce the MeCP2 binding to methylated DNA ${ }^{35}$. Based on the MeCP2-DNA complex structures, RTT-associated mutations in MBD can be classified into three groups: 1) are directly involved in base-specific interactions, such as the arginine fingers R111 and R133; 2) contact the DNA backbone by providing hydrogen bonding, electrostatic and/or Van Der Waals Interactions, such as S134C, K135E and T158M; and 3) not directly interact with the DNA ligand, and may affect binding indirectly by changing the overall protein stability or solubility, such as R106W, Y141, and D156 ${ }^{35,37}$. To test how these mutations affect their binding to the CAC DNA, we chose 6 high-frequency mutation points (R106W, S134C, K135E, Y141C, D156E and T158W), and carried out ITC assays. Of the three DNA-proximal mutants, the S134C and T158M mutants exhibited significantly reduced or disrupted binding, but the K135E only had slightly reduced binding (Fig. 5b). Although K135 is near DNA, but its side chain is exposed to the solvent, and its $\varepsilon$ ammonium group is not in contact with the DNA, and is disordered in our structures (Fig. 5a). Mutating R106W, Y141C, or D156E caused loss of the DNA binding ability (Fig. $5 b$ ), potentially due to reduced protein stability because all of these residues form extensive interactions with surrounding residues. Therefore, most of the RTT-associated mutations in the MeCP2-MBD cause Rett syndrome by diminishing or disrupting the MeCP2's ability in binding to its DNA ligands.

\section{Discussion}

As $\mathrm{MeCP} 2$ recruits histone deacetylases $(\mathrm{HDAC})^{4}$ and histone methyltransferases ${ }^{39}$ to 
methylated chromatin loci, a role for $\mathrm{MeCP} 2$ in transcription repression has been proposed $^{4,39}$. A recent ChiP-seq analysis has revealed that the genome wide distribution of MeCP2 is determined by the percentage of GC, not necessarily by the density of methylated $\mathrm{CG}$ dinucleotide ${ }^{40}$, suggesting that the location of MeCP2 is not always correlation with heavily methylated CG. Methylated non-CG motifs, such as mCAC, were found to bind $\mathrm{MeCP} 2$ in brain $^{9,10}$. MeCP2 also associates with unmethylated CAC/GTG containing DNA fragments, including the MARs/SARs DNA and mouse satellite DNA in vitro ${ }^{15-17}$. MARs/SARs DNA elements, which are evolutionarily conserved from yeast to human, might serve as chromatin loop anchors and play a role in the regulation of gene expression ${ }^{16,41,42}$. In interphase MCF7 cells, MeCP2 was found to be associated with four clones derived from putative MARs, but just one clone from CG islands $^{43}$. MeCP2 was found to activate the majority of its target genes in mouse hypothalamus, and corresponding promoters were not necessarily rich in $\mathrm{mCG}$ sites ${ }^{14}$. Clearly, MeCP2 association requires neither the $\mathrm{CG}$ motif nor cytosine methylation, significantly widening the repertoire of potential ligands beyond initial predictions.

Our ITC data confirmed that MeCP2 binds to DNA that contains the CAC/GTG trinucleotide motif, which was originally identified in some MARs/SARs DNA as the ligand of the $\mathrm{MeCP} 2$ chicken ortholog ${ }^{16}$. Our crystal structures revealed that bases of only the GTG trinucleotide interact with the residues R111 and R133 in MeCP2 MBD and that cytosine methylation on the complementary strand is not essential. Additionally, cytosine methylation in mCAC introduces an additional contact with a potential hydrogen bond acceptor on MeCP2 R133, the second-most commonly mutated MBD residue in RTT patients. The role of R133 in base recognition and the possibility of a weak interaction formed by the MBD main chain and a putative cytosine 5-methyl group together would explain our failure to detect binding between MeCP2 R133 mutants and unmethylated GTG DNA, while we still detected binding for mCAC and mCG DNA (Fig. 4c, d). The observations that 1) the R133 mutants are still able to bind to mCAC and mCG DNA but lack binding to CAC DNA, and 2) most of MeCP2-controlled genes are sparsely methylated lead us to speculate that the unmethylated CAC/GTG motif containing DNA is one major physiological ligand of $\mathrm{MeCP} 2$, which need to be further evaluated in the future. 


\section{Methods}

\section{Protein expression and purification}

Human MeCP2 (aa. 80-164) was subcloned into pET28-MHL expression vector to generate N-terminal His tag fused protein. The MeCP2-MBD mutants were obtained by Quick Change site-directed mutagenesis (Agilent Technologies) using the MeCP2 (aa. 80-164)-pET28-MHL plasmid as template. For crystallization, two other MeCP2-MBD (aa. 77-167 and aa. 77-166) fragments were subcloned into the pNIC-CH expression vector, respectively.

The recombinant proteins were overexpressed in Escherichia coli BL21 (DE3)-RIL strains and induced with $0.35 \mathrm{mM}$ isopropyl- $\beta$-d-thiogalactopyranoside (IPTG) at $16^{\circ} \mathrm{C}$ for overnight. The cell pellet was collected, and further dissolved in a buffer containing $20 \mathrm{mM}$ Tris-HCl, pH 7.5, $500 \mathrm{mM} \mathrm{NaCl}, 0.5 \mathrm{mM}$ PMSF and 5\% glycerol. The lysed cell supernatants were incubated with Ni-NTA resin (Qiagen) for $30 \mathrm{~min}$ before washing with lysis buffer with an additional $10 \mathrm{mM}$ imidazole. Finally, the purified proteins were eluted using $20 \mathrm{mM}$ Tris- $\mathrm{HCl}, \mathrm{pH} 7.5,500 \mathrm{mM} \mathrm{NaCl}$ and $300 \mathrm{mM}$ imidazole. For crystallization, the His tag in MeCP2 (aa. 80-164) fusion proteins was removed by tobacco etch virus (TEV). The proteins were further purified by anion-exchange column and gel filtration column (GE Healthcare). Finally, the purified proteins for ITC experiments were concentrated to $10 \mathrm{mg} / \mathrm{ml}$ in $20 \mathrm{mM}$ Tris- $\mathrm{HCl}, \mathrm{pH} 7.5$ and $150 \mathrm{mM}$ $\mathrm{NaCl}$. For crystallization, $1 \mathrm{mM}$ DTT was added in the ITC buffer.

\section{ITC Binding assay}

All the DNA oligos used for ITC and crystallization experiments were synthesized by IDT (Integrated DNA Technologies, USA) and processed as described before ${ }^{26}$. Simply, the single DNAs were dissolved in the same buffer as the target proteins, containing 20 $\mathrm{mM}$ Tris- $\mathrm{HCl}, \mathrm{pH} 7.5$ and $150 \mathrm{mM} \mathrm{NaCl}$, whose final $\mathrm{pH}$ was adjusted to around 7.5 using $\mathrm{NaOH}$. Then the single strand DNA was annealed into DNA duplex ${ }^{44}$. The concentrations of MeCP2 and DNA oligos used in ITC experiment are ranging from 30 to $80 \mu \mathrm{M}$ and $0.5 \mathrm{mM}$ to $1 \mathrm{mM}$, respectively. The concentrations of proteins and DNA are 
the average concentrations that were determined by Nano Drop (Thermo Scientific) over triple measurements. ITC measurements were carried out using MicroCal ITC or ITC200 (GE Healthcare) at $25^{\circ} \mathrm{C}$. The data were fitted using Origin 7.0 (MicroCal Inc.) with onesite binding model of the ITC data analysis module. The standard error of each Kd value reflects the fitting error for the best ITC titration curve. The detailed thermodynamic parameters have been reported in the Supplemental Table 1.

\section{Crystallization}

The purified proteins were mixed with DNA at a molar ratio approximately 1:1.3 by directly adding the DNA into the protein solution. After incubation on ice for 30 minutes, the protein-DNA reaction mixtures were crystallized using the sitting drop vapor diffusion at $18{ }^{\circ} \mathrm{C}$. The detailed crystallization conditions for each MeCP2 MBD-DNA complex were summarized in Table 1.

\section{Data collection and structure determination}

Crystals were soaked in a mixture of 1 part glycerol to between 4 and 6 parts of the relevant crystallization reagent prior to rapid immersion in liquid nitrogen for storage. Diffraction data were collected under cooling at the Advanced Photon Source (mCG complex), Canadian Light Source $(\mathrm{CAC})^{45}$ or Advanced Light Source (mCAC). Structures were solved by molecular replacement with the program PHASER ${ }^{46}$. For the mCG complex, search models were derived from PDB entry $3 c 2 i^{23}$ and a preliminary version of coordinates from PDB entry $6 \mathrm{cnq}^{26}$. Search models for the other complexes were derived from the $\mathrm{mCG}$ complex model. ARP/WARP ${ }^{47}$ was used to improve electron density maps for the $\mathrm{mCG}$ and $\mathrm{mCAC}$ complexes. Data collected on a rotating anode source from an additional, nearly isomorphous crystal were used to solve the structure of the mCAC complex, and DIMPLE (http://ccp4.github.io/dimple) scripts were used during refinement of that complex's atomic model. Models were interactively rebuilt with $\mathrm{COOT}^{48}$ and refined with REFMAC ${ }^{49}$ or PHENIX ${ }^{50}$. Model geometry was evaluated with MOLPROBITY ${ }^{51}$. Data collection and refinement statistics were summarized in Table 1.

\section{Acknowledgements}


GM/CA@APS has been funded in whole or in part by the National Cancer Institute (ACB-12002) and the National Institute of General Medical Sciences (AGM-12006). This research used resources of the Advanced Photon Source, a U.S. Department of Energy (DOE) Office of Science User Facility operated for the DOE Office of Science by Argonne National Laboratory under Contract No. DE-AC02-06CH11357. Research described in this paper was performed using beamline 08ID-1 at the Canadian Light Source, which is supported by the Canada Foundation for Innovation, Natural Sciences and Engineering Research Council of Canada, the University of Saskatchewan, the Government of Saskatchewan, Western Economic Diversification Canada, the National Research Council Canada, and the Canadian Institutes of Health Research. The Berkeley Center for Structural Biology is supported in part by the Howard Hughes Medical Institute. The Advanced Light Source is a Department of Energy Office of Science User Facility under Contract No. DE-AC02-05CH11231. The Pilatus detector on 5.0.1, was funded under NIH grant S10OD021832. The ALS-ENABLE beamlines are supported in part by the National Institutes of Health, National Institute of General Medical Sciences, grant P30 GM124169. The SGC is a registered charity (number 1097737) that receives funds from AbbVie, Bayer Pharma AG, Boehringer Ingelheim, Canada Foundation for Innovation, Eshelman Institute for Innovation, Genome Canada through Ontario Genomics Institute [OGI-055], Innovative Medicines Initiative (EU/EFPIA) [ULTRADD grant no. 115766], Janssen, Merck KGaA, Darmstadt, Germany, MSD, Novartis Pharma AG, Ontario Ministry of Research, Innovation and Science (MRIS), Pfizer, São Paulo Research Foundation-FAPESP, Takeda, and Wellcome. We also thank Dr. Zhang Delin at Center for Protein Research (CPR), Huazhong Agricultural University for technical support.

\section{AUTHOR CONTRIBUTIONS}

K.L and J.M. conceived the project. M.L. and K.L. designed and performed crystallization and binding experiments and data analysis. W.T. determined the crystal structures. K.L and J.M. wrote the manuscript with significant contributions from the other authors.

\section{COMPETING FINANCIAL INTERESTS}


bioRxiv preprint doi: https://doi.org/10.1101/581934; this version posted March 18,2019 . The copyright holder for this preprint (which was not certified by peer review) is the author/funder. All rights reserved. No reuse allowed without permission.

The authors declare no competing financial interest. 


\section{References:}

1 Lewis, J. D. et al. Purification, sequence, and cellular localization of a novel chromosomal protein that binds to methylated DNA. Cell 69, 905-914 (1992).

2 Meehan, R. R., Lewis, J. D. \& Bird, A. P. Characterization of MeCP2, a vertebrate DNA binding protein with affinity for methylated DNA. Nucleic acids research 20, 5085-5092 (1992).

3 Kruusvee, V. et al. Structure of the MeCP2-TBLR1 complex reveals a molecular basis for Rett syndrome and related disorders. Proceedings of the National Academy of Sciences of the United States of America 114, E3243-E3250, doi:10.1073/pnas.1700731114 (2017).

4 Nan, X. et al. Transcriptional repression by the methyl-CpG-binding protein MeCP2 involves a histone deacetylase complex. Nature 393, 386-389, doi:10.1038/30764 (1998).

5 Skene, P. J. et al. Neuronal MeCP2 is expressed at near histone-octamer levels and globally alters the chromatin state. Molecular cell 37, 457-468, doi:10.1016/j.molcel.2010.01.030 (2010).

6 Amir, R. E. et al. Rett syndrome is caused by mutations in X-linked MECP2, encoding methyl-CpG-binding protein 2. Nature genetics 23, 185-188, doi:10.1038/13810 (1999).

7 Qiu, Z. Deciphering MECP2-associated disorders: disrupted circuits and the hope for repair. Current opinion in neurobiology 48, 30-36, doi:10.1016/j.conb.2017.09.004 (2018).

8 Guo, J. U. et al. Distribution, recognition and regulation of non-CpG methylation in the adult mammalian brain. Nature neuroscience 17, 215-222, doi:10.1038/nn.3607 (2014).

9 Gabel, H. W. et al. Disruption of DNA-methylation-dependent long gene repression in Rett syndrome. Nature 522, 89-93, doi:10.1038/nature14319 (2015).

10 Lagger, S. et al. MeCP2 recognizes cytosine methylated tri-nucleotide and dinucleotide sequences to tune transcription in the mammalian brain. PLoS genetics 13, e1006793, doi:10.1371/journal.pgen.1006793 (2017).

11 Kinde, B., Gabel, H. W., Gilbert, C. S., Griffith, E. C. \& Greenberg, M. E. Reading the unique DNA methylation landscape of the brain: Non-CpG methylation, hydroxymethylation, and MeCP2. Proceedings of the National Academy of Sciences of the United States of America 112, 6800-6806, doi:10.1073/pnas.1411269112 (2015).

12 Kinde, B., Wu, D. Y., Greenberg, M. E. \& Gabel, H. W. DNA methylation in the gene body influences MeCP2-mediated gene repression. Proceedings of the National Academy of Sciences of the United States of America 113, 15114-15119, doi:10.1073/pnas.1618737114 (2016).

13 Yasui, D. H. et al. Integrated epigenomic analyses of neuronal MeCP2 reveal a role for long-range interaction with active genes. Proceedings of the National Academy of Sciences of the United States of America 104, 19416-19421, doi:10.1073/pnas.0707442104 (2007). 
14 Chahrour, M. et al. MeCP2, a key contributor to neurological disease, activates and represses transcription. Science $\mathbf{3 2 0}$, 1224-1229, doi:10.1126/science.1153252 (2008).

15 Weitzel, J. M., Buhrmester, H. \& Stratling, W. H. Chicken MAR-binding protein ARBP is homologous to rat methyl-CpG-binding protein MeCP2. Molecular and cellular biology 17, 5656-5666 (1997).

16 von Kries, J. P., Buhrmester, H. \& Stratling, W. H. A matrix/scaffold attachment region binding protein: identification, purification, and mode of binding. Cell 64, 123-135 (1991).

17 Buhrmester, H., von Kries, J. P. \& Stratling, W. H. Nuclear matrix protein ARBP recognizes a novel DNA sequence motif with high affinity. Biochemistry 34, 4108-4117 (1995).

18 Stief, A., Winter, D. M., Stratling, W. H. \& Sippel, A. E. A nuclear DNA attachment element mediates elevated and position-independent gene activity. Nature 341, 343-345, doi:10.1038/341343a0 (1989).

19 Klehr, D., Maass, K. \& Bode, J. Scaffold-attached regions from the human interferon beta domain can be used to enhance the stable expression of genes under the control of various promoters. Biochemistry 30, 1264-1270 (1991).

20 Liu, J. W. \& Tabe, L. M. The influences of two plant nuclear matrix attachment regions (MARs) on gene expression in transgenic plants. Plant \& cell physiology 39, 115-123 (1998).

21 Breyne, P., van Montagu, M., Depicker, N. \& Gheysen, G. Characterization of a plant scaffold attachment region in a DNA fragment that normalizes transgene expression in tobacco. The Plant cell 4, 463-471 (1992).

22 Poljak, L., Seum, C., Mattioni, T. \& Laemmli, U. K. SARs stimulate but do not confer position independent gene expression. Nucleic acids research 22, 43864394 (1994).

23 Ho, K. L. et al. MeCP2 binding to DNA depends upon hydration at methyl-CpG. Molecular cell 29, 525-531, doi:10.1016/j.molcel.2007.12.028 (2008).

24 Chen, W. G. et al. Derepression of BDNF transcription involves calciumdependent phosphorylation of MeCP2. Science 302, 885-889, doi:10.1126/science.1086446 (2003).

25 Hansen, J. C., Ghosh, R. P. \& Woodcock, C. L. Binding of the Rett syndrome protein, $\mathrm{MeCP} 2$, to methylated and unmethylated DNA and chromatin. IUBMB life 62, 732-738, doi:10.1002/iub.386 (2010).

26 Liu, K. et al. Structural basis for the ability of MBD domains to bind methyl-CG and TG sites in DNA. The Journal of biological chemistry 293, 7344-7354, doi:10.1074/jbc.RA118.001785 (2018).

27 Chia, J. Y. et al. A/T Run Geometry of B-form DNA Is Independent of Bound Methyl-CpG Binding Domain, Cytosine Methylation and Flanking Sequence. Scientific reports 6, 31210, doi:10.1038/srep31210 (2016).

28 Lister, R. et al. Global epigenomic reconfiguration during mammalian brain development. Science 341, 1237905, doi:10.1126/science.1237905 (2013).

29 Yesselman, J. D., Horowitz, S., Brooks, C. L., 3rd \& Trievel, R. C. Frequent side chain methyl carbon-oxygen hydrogen bonding in proteins revealed by 
computational and stereochemical analysis of neutron structures. Proteins 83, 403-410, doi:10.1002/prot.24724 (2015).

30 Ohki, I. et al. Solution structure of the methyl-CpG binding domain of human MBD1 in complex with methylated DNA. Cell 105, 487-497 (2001).

31 Scarsdale, J. N., Webb, H. D., Ginder, G. D. \& Williams, D. C., Jr. Solution structure and dynamic analysis of chicken MBD2 methyl binding domain bound to a target-methylated DNA sequence. Nucleic acids research 39, 6741-6752, doi:10.1093/nar/gkr262 (2011).

32 Walavalkar, N. M., Cramer, J. M., Buchwald, W. A., Scarsdale, J. N. \& Williams, D. C., Jr. Solution structure and intramolecular exchange of methyl-cytosine binding domain protein 4 (MBD4) on DNA suggests a mechanism to scan for $\mathrm{mCpG} / \mathrm{TpG}$ mismatches. Nucleic acids research 42, 11218-11232, doi:10.1093/nar/gku782 (2014).

33 Otani, J. et al. Structural basis of the versatile DNA recognition ability of the methyl-CpG binding domain of methyl-CpG binding domain protein 4 . The Journal of biological chemistry 288, 6351-6362, doi:10.1074/jbc.M112.431098 (2013).

34 Ausio, J., Martinez de Paz, A. \& Esteller, M. MeCP2: the long trip from a chromatin protein to neurological disorders. Trends in molecular medicine 20, 487-498, doi:10.1016/j.molmed.2014.03.004 (2014).

35 Yang, Y., Kucukkal, T. G., Li, J., Alexov, E. \& Cao, W. Binding Analysis of Methyl-CpG Binding Domain of MeCP2 and Rett Syndrome Mutations. ACS chemical biology 11, 2706-2715, doi:10.1021/acschembio.6b00450 (2016).

36 D'Annessa, I. et al. Tyr120Asp mutation alters domain flexibility and dynamics of MeCP2 DNA binding domain leading to impaired DNA interaction: Atomistic characterization of a Rett syndrome causing mutation. Biochimica et biophysica acta. General subjects 1862, 1180-1189, doi:10.1016/j.bbagen.2018.02.005 (2018).

37 Kucukkal, T. G., Yang, Y., Uvarov, O., Cao, W. \& Alexov, E. Impact of Rett Syndrome Mutations on MeCP2 MBD Stability. Biochemistry 54, 6357-6368, doi:10.1021/acs.biochem.5b00790 (2015).

38 Yusufzai, T. M. \& Wolffe, A. P. Functional consequences of Rett syndrome mutations on human MeCP2. Nucleic acids research 28, $4172-4179$ (2000).

39 Fuks, F. et al. The methyl-CpG-binding protein MeCP2 links DNA methylation to histone methylation. The Journal of biological chemistry 278, 4035-4040, doi:10.1074/jbc.M210256200 (2003).

40 Rube, H. T. et al. Sequence features accurately predict genome-wide MeCP2 binding in vivo. Nature communications 7, 11025, doi:10.1038/ncomms11025 (2016).

41 Bode, J. \& Maass, K. Chromatin domain surrounding the human interferon-beta gene as defined by scaffold-attached regions. Biochemistry 27, 4706-4711 (1988).

42 Mirkovitch, J., Mirault, M. E. \& Laemmli, U. K. Organization of the higher-order chromatin loop: specific DNA attachment sites on nuclear scaffold. Cell 39, 223232 (1984). 
43 Koch, C. \& Stratling, W. H. DNA binding of methyl-CpG-binding protein $\mathrm{MeCP} 2$ in human MCF7 cells. Biochemistry 43, 5011-5021, doi:10.1021/bi0359271 (2004).

$44 \mathrm{Xu}, \mathrm{Y}$. et al. Tet3 CXXC domain and dioxygenase activity cooperatively regulate key genes for Xenopus eye and neural development. Cell 151, 1200-1213, doi:10.1016/j.cell.2012.11.014 (2012).

45 Grochulski, P., Fodje, M. N., Gorin, J., Labiuk, S. L. \& Berg, R. Beamline 08ID-1, the prime beamline of the Canadian Macromolecular Crystallography Facility. Journal of synchrotron radiation 18, 681-684, doi:10.1107/S0909049511019431 (2011).

46 McCoy, A. J. et al. Phaser crystallographic software. Journal of applied crystallography 40, 658-674, doi:10.1107/S0021889807021206 (2007).

47 Perrakis, A., Sixma, T. K., Wilson, K. S. \& Lamzin, V. S. wARP: improvement and extension of crystallographic phases by weighted averaging of multiplerefined dummy atomic models. Acta crystallographica. Section D, Biological crystallography 53, 448-455, doi:10.1107/S0907444997005696 (1997).

48 Emsley, P., Lohkamp, B., Scott, W. G. \& Cowtan, K. Features and development of Coot. Acta crystallographica. Section D, Biological crystallography 66, 486501, doi:10.1107/S0907444910007493 (2010).

49 Murshudov, G. N. et al. REFMAC5 for the refinement of macromolecular crystal structures. Acta crystallographica. Section D, Biological crystallography 67, 355367, doi:10.1107/S0907444911001314 (2011).

50 Adams, P. D. et al. PHENIX: a comprehensive Python-based system for macromolecular structure solution. Acta crystallographica. Section D, Biological crystallography 66, 213-221, doi:10.1107/S0907444909052925 (2010).

51 Chen, V. B. et al. MolProbity: all-atom structure validation for macromolecular crystallography. Acta crystallographica. Section D, Biological crystallography 66, 12-21, doi:10.1107/S0907444909042073 (2010). 


\section{Figure legends}

Fig. 1 MeCP2-MBD specifically binds to unmethylated CAC/GTG motif containing DNA fragment from MARs. The ITC binding curves of the MeCP2-MBD to a native MARs DNA fragment (a) and a mutated MARs DNA fragment (b).

Fig. 2 Structural basis for the recognition of CAC, mCG and mCAC by MeCP2MBD. (a, d and g) Overall structures of MeCP2-MBD in complex respectively with CAC, mCG and mCAC DNA, respectively. The protein part is shown in blue cartoon representation, while the DNA ligand is shown in green cartoon representation. The nucleotides involved in base interactions are shown in stick models: G5-C5' (grey), mC6G6' or TC6-A6' (yellow), G7-mC7' or G7-C7' (red). The base interacting protein residues in MeCP2 are shown in stick models and water molecules are shown in red spheres. The hydrogen bonds formed between protein residues and DNA are marked as black dashed lines, while the grey dashed lines represent the hydrogen bonds between base pairs. In (g), the non-conventional C-O hydrogen bond between 5-methyl group of the methylated cytosine in the mCAC/GTG sequence and the main chain carbonyl oxygen of R133 was colored as purple. (b, e and h) Detailed interactions of different DNA with MeCP2-MBD. The interacting residues and DNA bases are shown in the same mode as in (a, d and g), respectively. The hydrogen bonds formed by protein residues and DNA are marked as black dashed lines, while the grey dashed lines represent the hydrogen bonds between base pairs. In (h), the non-conventional C-O hydrogen bond between 5-methyl group of the methylated cytosine in the mCAC/GTG sequence and the main chain carbonyl oxygen of R133 was colored as purple. (c, f and i) Schematic diagram of the detailed interactions between MeCP2-MBD and different DNA. Direct and water-mediated hydrogen bonds are indicated by solid and dash red arrows, respectively. The stacking interactions between Arginine fingers and bases are indicated by grey arrows.

Fig. 3 Structural comparisons of MeCP2 and MBD2 MBDs in complex with different DNA. (a) Structural comparisons of MeCP2-MBD in complex with CAC/GTG 
and mCAC/GTG DNA. Hydrogen bonds formed by protein and DNA are shown as the black dashed lines, the interaction between DNA base pairs are shown as grey dashed lines. The non-conventional $\mathrm{C}$-O hydrogen bond between 5-methyl group of the methylated cytosine in the mCAC/GTG sequence and the main chain carbonyl oxygen of R133 was colored as purple. (b) Structural comparisons of MeCP2-MBD in complex with CAC/GTG and mCG DNA. Hydrogen bonds formed by protein and DNA are shown as the black dashed lines, the interaction between DNA base pairs are shown as grey dashed lines. (c) Structural comparisons of MBD2-CAC (grey), MBD2-mCAC (pink), MeCP2-CAC (blue), MeCP2-mCAC (Yellow), , and MeCP2-mCG (green) complexes. Arg133 of MeCP2 and Arg188 of MBD2 are shown in sticks. Hydrogen bonds formed by protein and DNA are shown as the black dashed lines.

Fig. 4 The R111A, R11G, R133A and $\mathrm{R} 133 \mathrm{C}$ mutations of MeCP2 reduce its DNA binding ability. (a) ITC binding curves of the MeCP2 R111A mutant to different DNA. (b) ITC binding curves of the MeCP2 R111G mutant to different DNA. (c) ITC binding curves of the MeCP2 R133A mutant to different DNA. (d) ITC binding curves of the MeCP2 R133C mutant to different DNA. WB: Weak binding.

\section{Fig. 5 Effect of Rett Syndrome mutations of MeCP2-MBD on its binding to} CAC/GTG DNA. (a) Locations of some high-frequency mutations on the MeCP2-MBD. The protein (blue) and CAC DNA (green) are shown in cartoon representation, and mutated residues in the MeCP2-MBD are shown as stick models. (b) ITC binding curves of 6 chosed MeCP2-MBD mutations to CAC DNA. WB: Weak binding. NB: No detectable binding. 
a

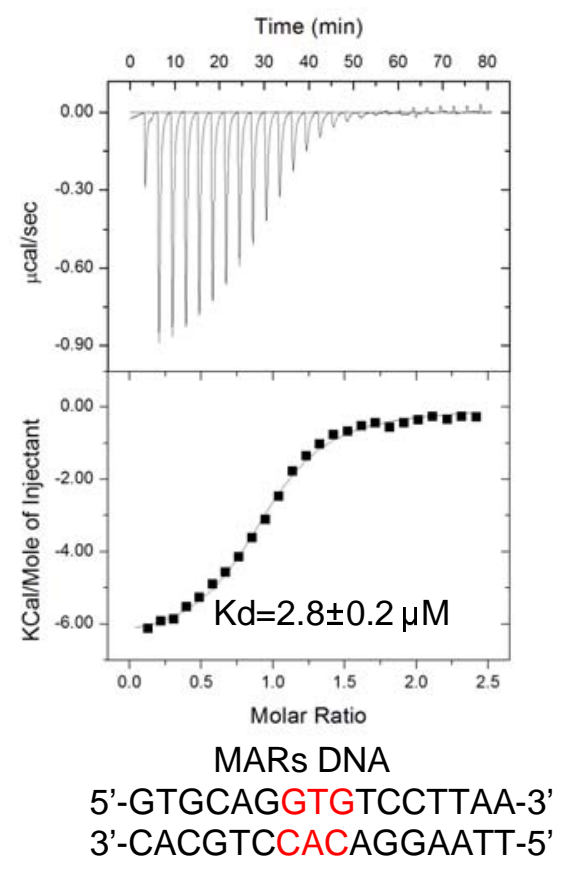

b

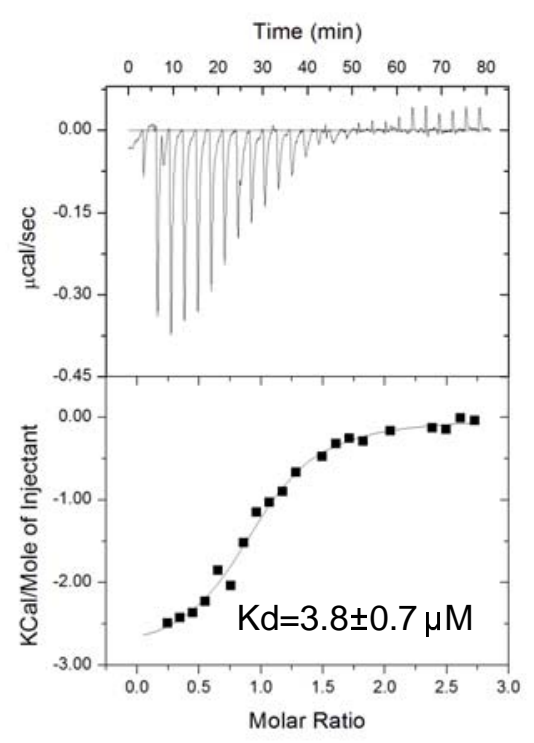

Mutated MARs DNA

5'-GCCCTGGTGTAGTGGC-3' 3'-CGGGACCACATCACCG-5' 

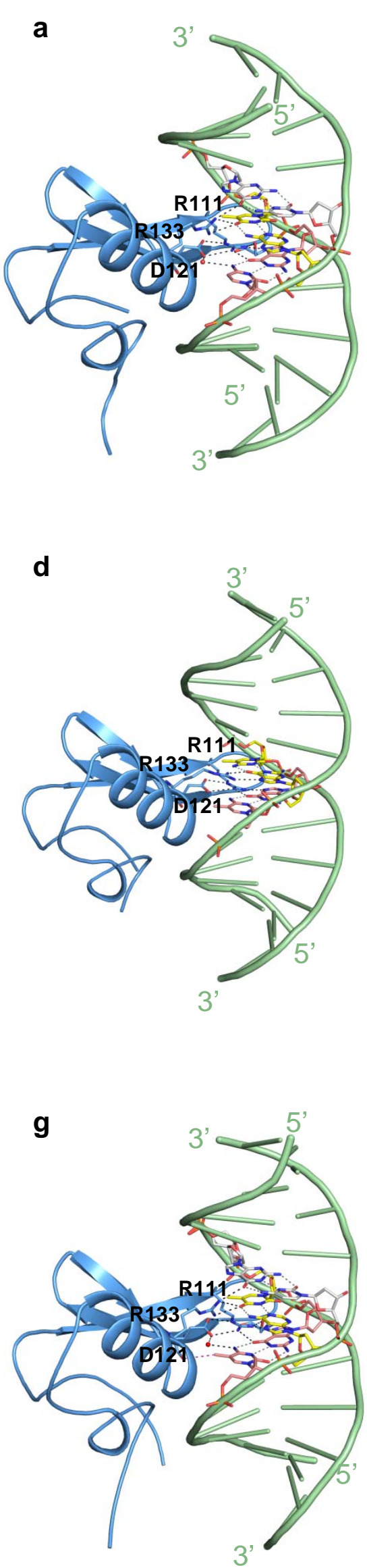

b

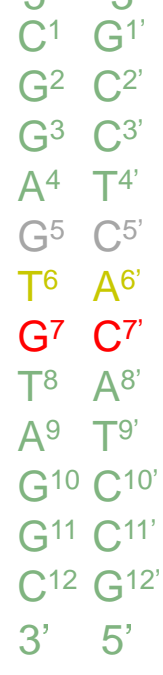

5' 3'

$G^{1} C^{1}$

$C^{2} \quad G^{2}$

$\mathrm{C}^{3} \quad \mathrm{G}^{3}$

$\mathrm{A}^{4} \quad \mathrm{~T}^{4}$

$C^{5} \quad G^{5}$

$\mathrm{mC}^{6} \mathrm{G}^{6}$

$\mathrm{G}^{7} \quad \mathrm{mC}^{7}$

$G^{8} \quad C^{8}$

$T^{9} \quad A^{9}$

$\mathrm{G}^{10} \mathrm{C}^{10}$

$\mathrm{G}^{11} \mathrm{C}^{11}$

$\mathrm{C}^{12} \quad \mathrm{G}^{12}$

3' 5'

e

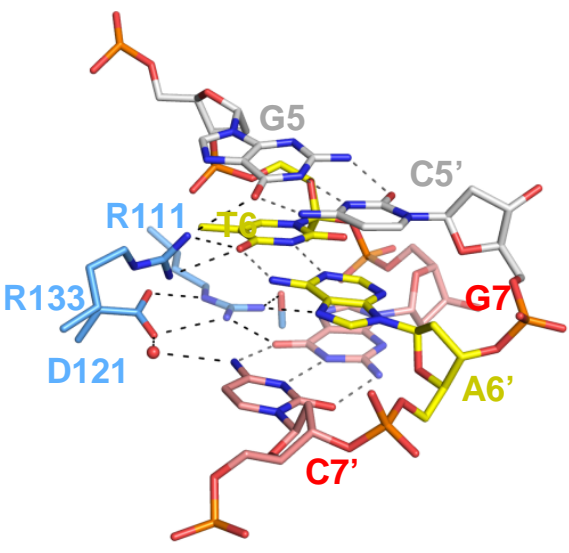

MeCP2-CAC/GTG

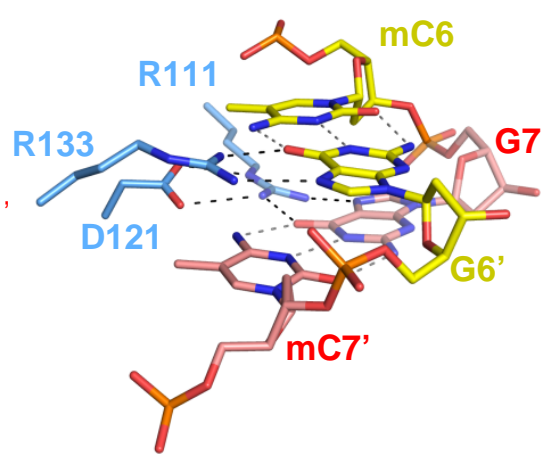

MeCP2-mCG/GmC
C

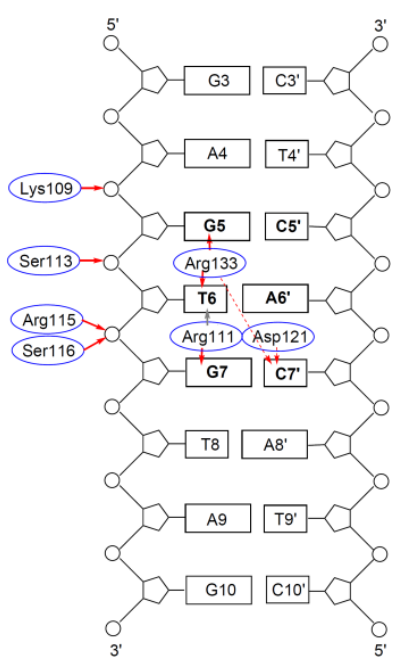

f

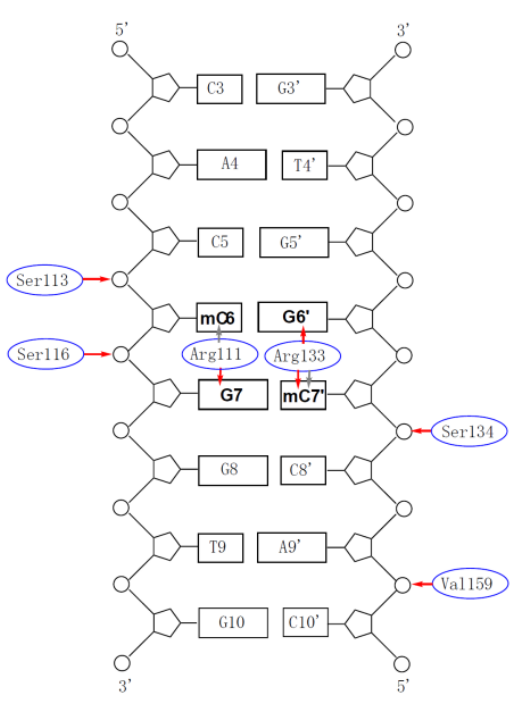

Figure 2

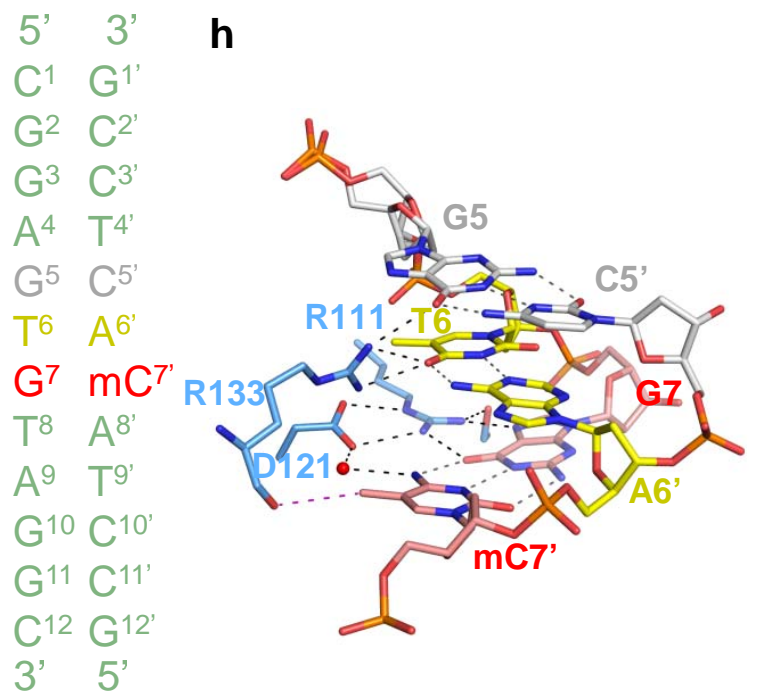

MeCP2-mCAC/GTG

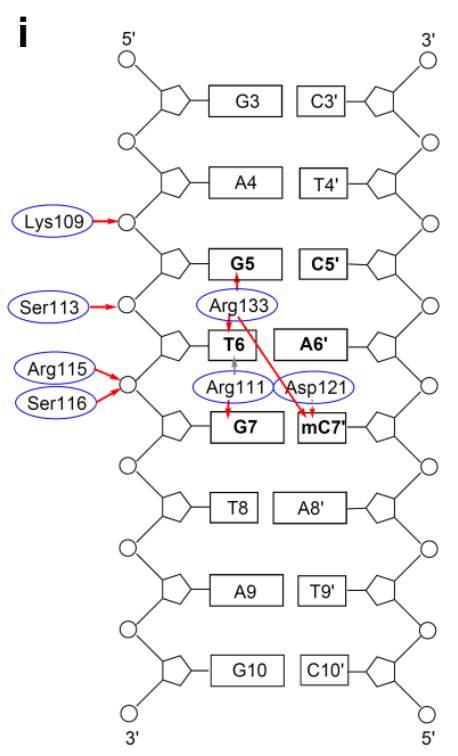


bioRxiv preprint doi: https://doi.org/10.1101/581934; this version posted March 18, 2019. The copyright holder for this preprint (which was not certified by peer review) is the author/funder. All rights reserved. No reuse allowed without permission.

a

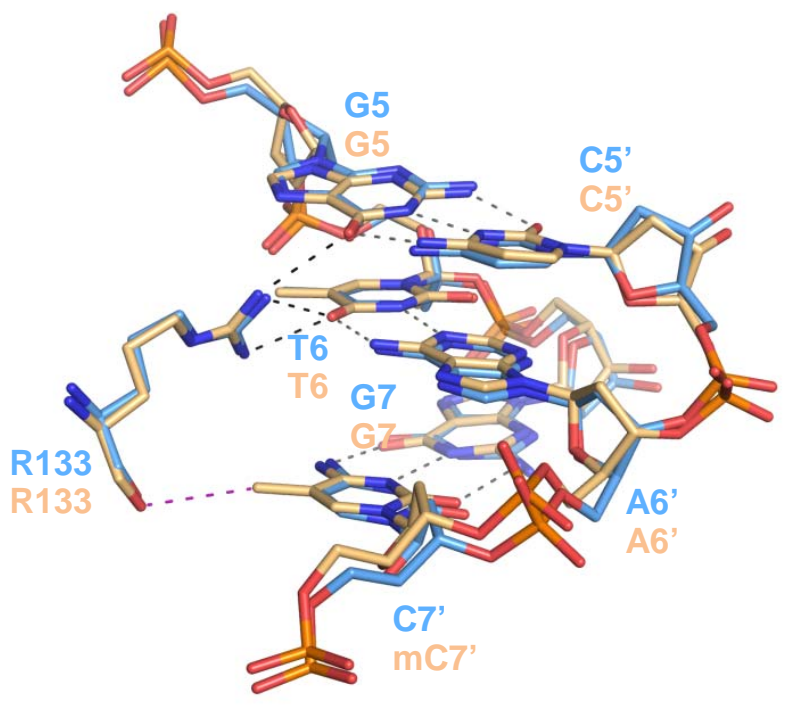

MeCP2-CAC/GTG MeCP2-mCAC/GTG b

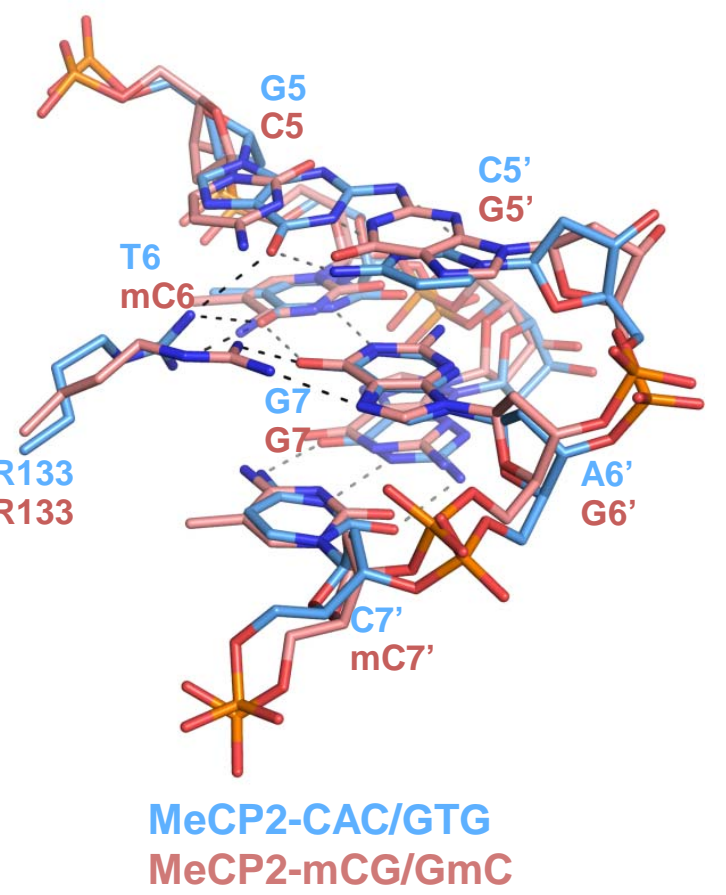

\section{C}

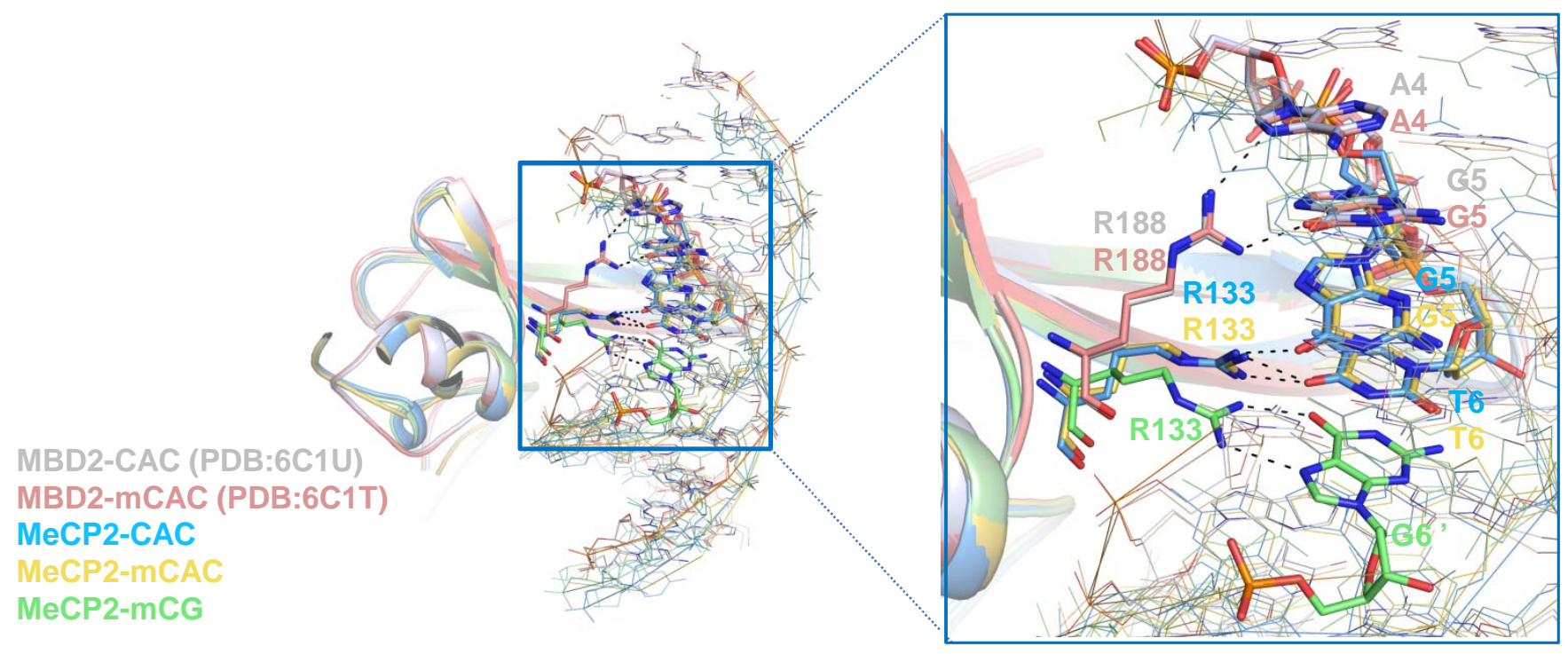

Figure 3 
bioRxiv preprint doi: https://doi.org/10.1101/581934; this version posted March 18, 2019. The copyright holder for this preprint (which was not certified by peer review) is the author/funder. All rights reserved. No reuse allowed without permission.

a

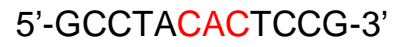
3'-CGGATGTGAGGC-5'

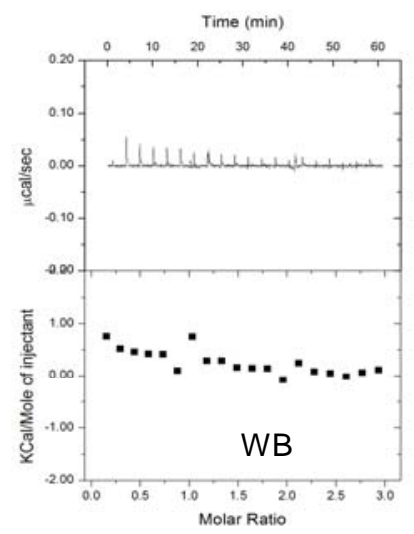

MeCP2R111A-CAC

b

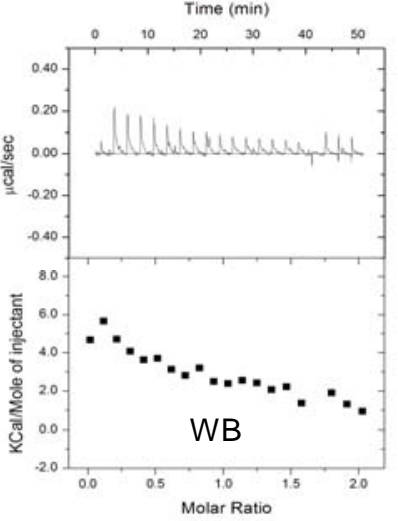

MeCP2R111G-CAC

C

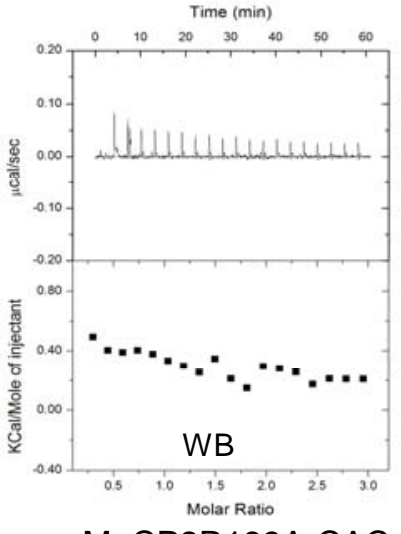

d

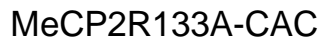

Time (min)

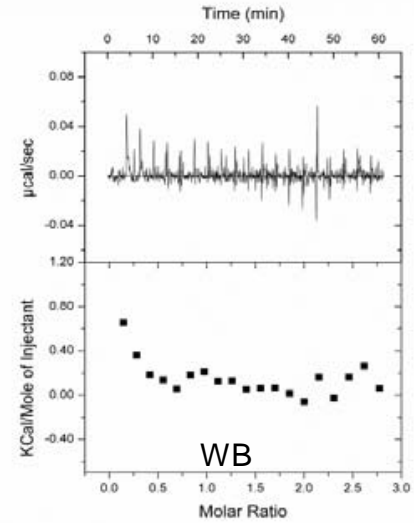

Figure 4 MeCP2R133C-CAC
5'-GCCTAMCACTCCG-3' 3'-CGGATGTGAGGC-5'

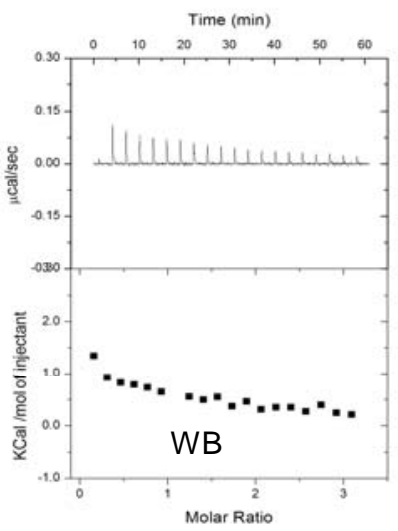

MeCP2R111A-mCAC

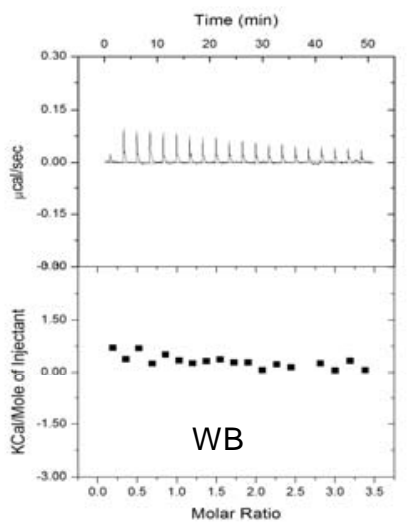

MeCP2R111G-mCAC

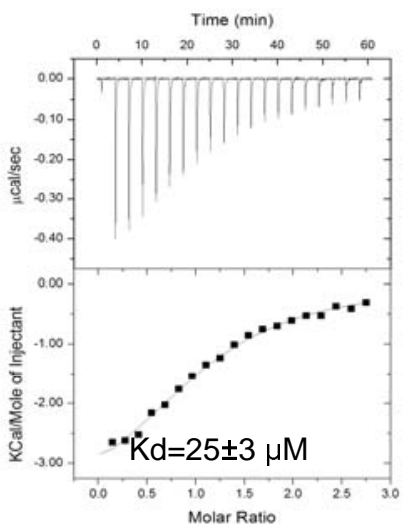

MeCP2R133A-mCAC

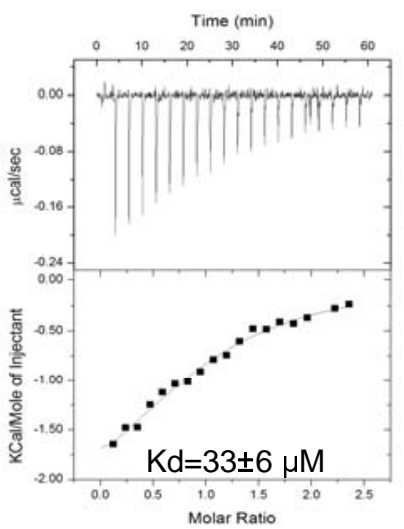

MeCP2R133C-mCAC
5'-GCCAGmCGCTGGC-3'

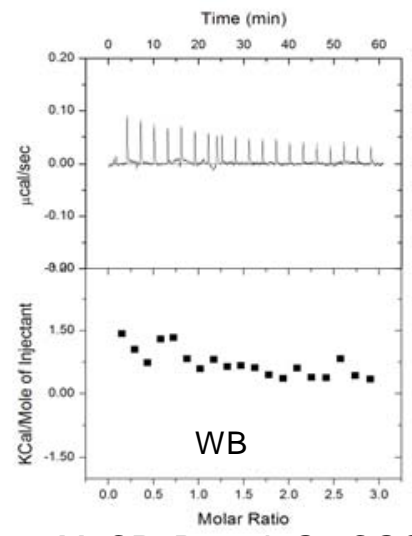

MeCP2R111A-GmCGC

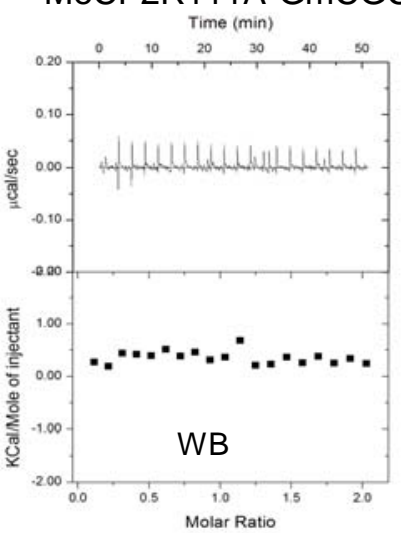

MeCP2R111G-GmCGC

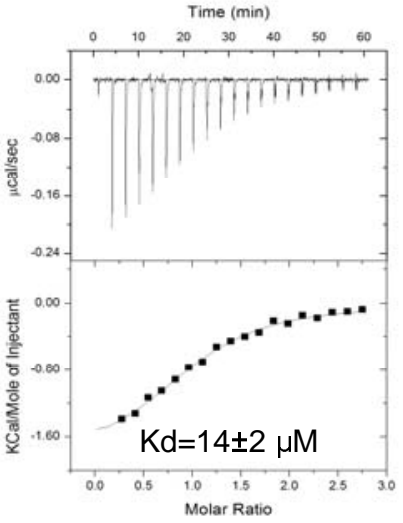

MeCP2R133A-GmCGC

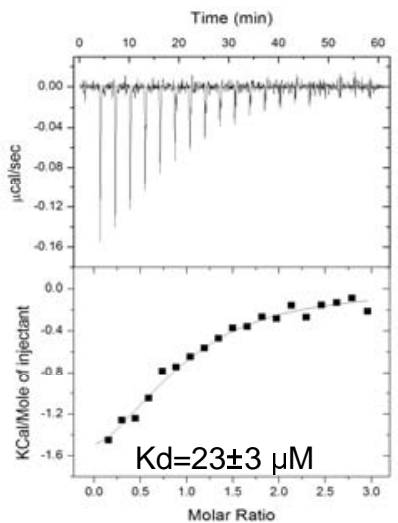

MeCP2R133C-GmCGC 
a

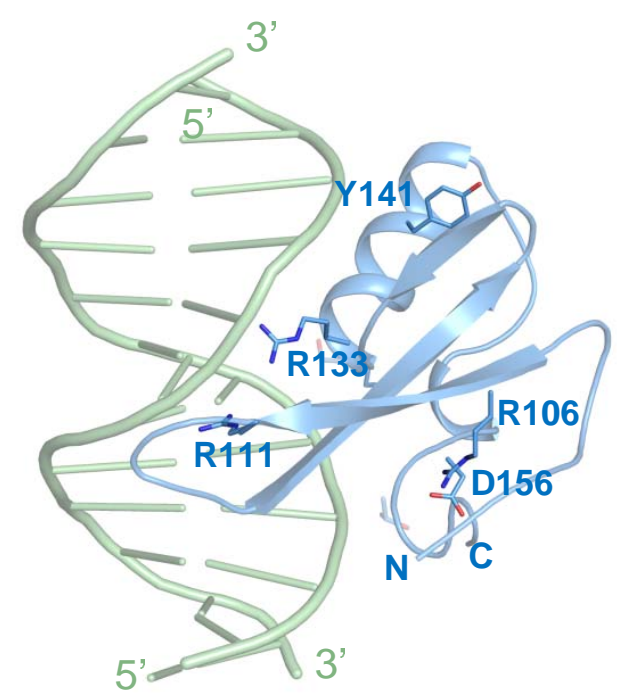

b
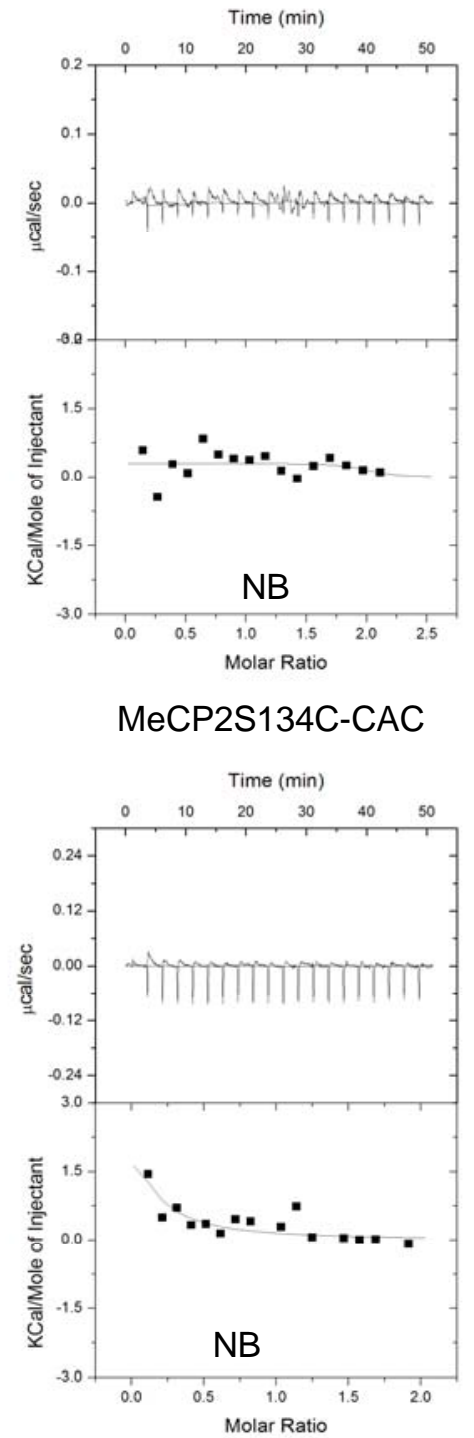

MeCP2R106W-CAC
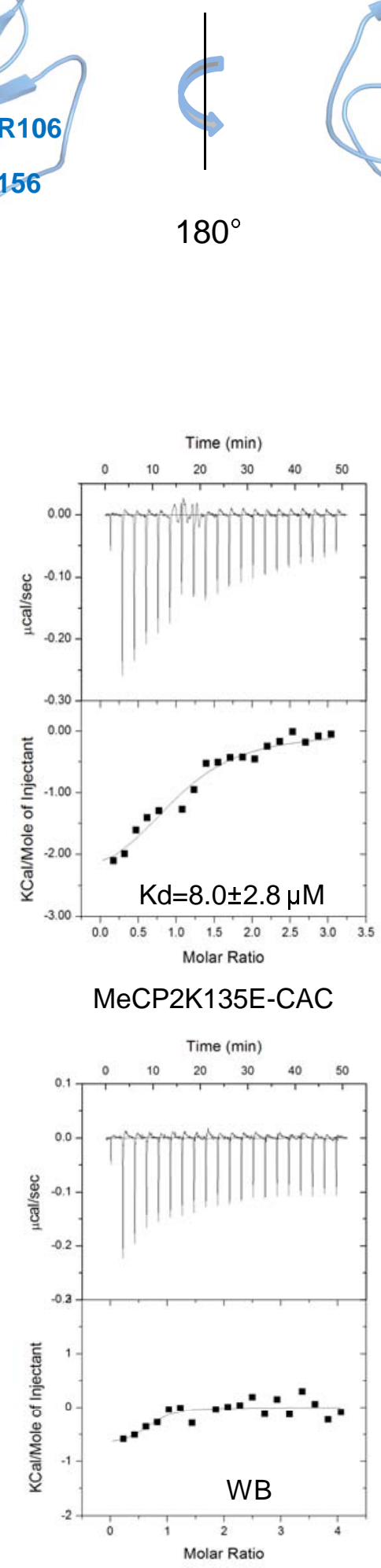

MeCP2Y141C-CAC

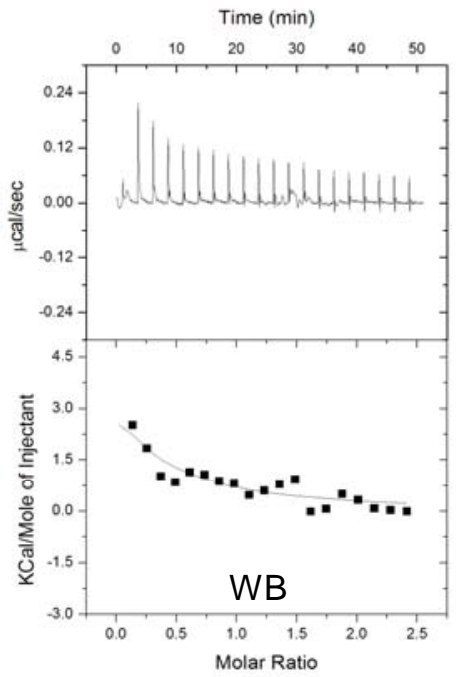

MeCP2T158W-CAC

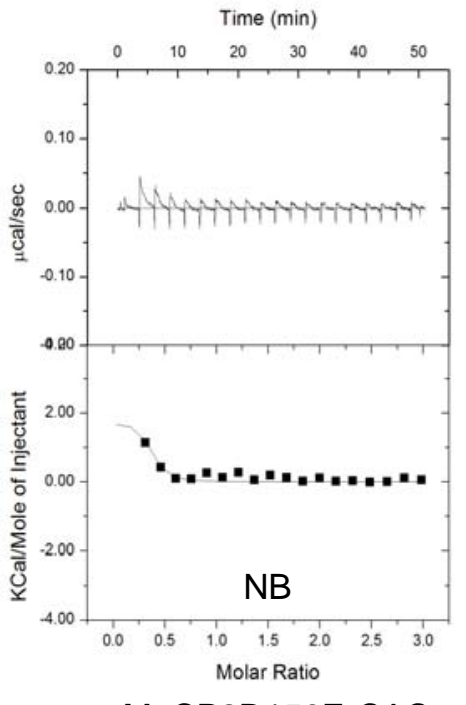

MeCP2D156E-CAC

Figure 5 


\section{Table 1. Data collection and refinement statistics of the MeCP2 MBD in complex with different DNA sequences}

\begin{tabular}{|c|c|c|c|}
\hline & MeCP2 (aa 80-164) & MeCP2 (aa 77-166) & MeCP2 (aa 77-167) \\
\hline DNA sequence & 5'-GCCAC $\underline{\text { ' }}$ CGGTGGC-3' & $\begin{array}{l}\text { 5'- GCCTACACTCCG-3' } \\
\text { 3'- CGGATGTGAGGC-5' }\end{array}$ & $\begin{array}{l}\text { 5'- GCCTAmCACTCCG-3' } \\
\text { 3'- CGGATGTGAGGC-5' }\end{array}$ \\
\hline Crystallization Buffer & $\begin{array}{c}\text { 25\% PEG3350, } 0.1 \mathrm{M} \\
\text { ammonium sulfate, } 0.1 \mathrm{M} \\
\text { tris, } \mathrm{pH} 8.5\end{array}$ & $\begin{array}{c}\text { 30\% PEG } 2000 \mathrm{MME}, \\
0.2 \mathrm{M} \mathrm{KBr}\end{array}$ & $\begin{array}{c}\text { 0.1 M Imidazole and MES } \\
\text { monohydrate (acid), pH } \\
\text { 6.5,0.018 M Magnesium } \\
\text { chloride hexahydrate and } \\
0.018 \mathrm{M} \text { Calcium chloride } \\
\text { dihydrate, } 12.5 \% \text { v/v MPD; } \\
\text { 12.5\% PEG 1000; } 12.5 \% \\
\text { w/v PEG 3350. }\end{array}$ \\
\hline \multicolumn{4}{|l|}{ Data Collection } \\
\hline Space group & $\mathrm{P} 1$ & $\mathrm{P} 2_{1}$ & $\mathrm{P} 2{ }_{1} 2_{1} 2_{1}$ \\
\hline \multicolumn{4}{|l|}{ Cell dimensions } \\
\hline $\mathrm{a}, \mathrm{b}, \mathrm{c}[\AA]$ & $40.75,47.36,54.62$ & $29.72,90.18,40.52$ & $40.47,51.98,66.30$ \\
\hline$\alpha, \beta, \gamma\left[^{\circ}\right]$ & $68.15,89.83,65.98$ & $90,92.57,90$ & $90,90,90$ \\
\hline Resolution $[\AA]$ & $39.85-2.30(2.38-2.30)$ & $45.09-1.80(1.83-1.80)$ & $40.91-1.60(1.63-1.60)$ \\
\hline Completeness [\%] & $96.3(84.2)$ & $98.6(94.1)$ & $99.8(97.3)$ \\
\hline Rsym & $0.068(0.449)$ & $0.047(1.111)$ & $0.060(1.835)$ \\
\hline I/sigmal & $10.1(2.4)$ & $12.0(0.9)$ & $17.5(0.7)$ \\
\hline Redundancy & $2.2(2.1)$ & $3.3(3.0)$ & $6.1(4.1)$ \\
\hline \multicolumn{4}{|l|}{ Refinement } \\
\hline Resolution [ $\mathrm{A}]$ & $39.85-2.30$ & $45.09-1.80$ & $40.90-1.65$ \\
\hline Reflections used & $13799 / 785$ & $18390 / 1109$ & $15648 / 1773$ \\
\hline No. atoms/ B-factor $\left[\AA^{* * 2}\right]$ & $2069 / 68.0$ & $1703 / 41.9$ & $1157 / 32.3$ \\
\hline Protein & $1090 / 69.1$ & $1169 / 43.9$ & $585 / 29.3$ \\
\hline DNA & $976 / 66.9$ & $485 / 37.5$ & $498 / 36.4$ \\
\hline Water & not applicable & $41 / 38.1$ & $56 / 27.7$ \\
\hline $\mathrm{R}$ work/free & $0.231 / 0.286$ & $0.226 / 0.256$ & $0.226(0.255)$ \\
\hline RMSD bonds $[\AA]] /$ angles $\left[{ }^{\circ}\right]$ & $0.016 / 1.7$ & $0.011 / 1.5$ & $0.011 / 1.7$ \\
\hline
\end{tabular}

*Values in parentheses are for highest-resolution shell. 